\title{
A tecnologia no auxílio à inserção dos temas transversais aos conteúdos das disciplinas do Ensino Fundamental: Uma experiência na Região Norte.
}

\author{
Deivid Eive Silva ${ }^{1}$, Kássia L. Souza ${ }^{1}$, Vanessa O. Silva ${ }^{1}$, Alleff Cristhian S. Sousa ${ }^{1}$, Igor \\ Mayco P. Oliveira ${ }^{1}$, Marialina Corrêa Sobrinho ${ }^{2}$, Marla T.B. Geller ${ }^{2}$ \\ ${ }^{1}$ Bolsistas PROICT Curso de Sistemas de Informação - Centro Universitário Luterano de \\ Santarém (CEULS/ULBRA) Santarém - PA - Brasil. \\ ${ }^{2}$ Curso de Sistemas de Informação - Centro Universitário Luterano de Santarém \\ (CEULS/ULBRA) Santarém - PA - Brasil - Orientadoras do projeto. \\ Deivid.eive@gmail.com, alleffcristhian@gmail.com, igormayco@gmail.com, \\ kassiia.souzalgmail.com, vanessaperola19@gmail.com
}

\begin{abstract}
Resumo
Os temas transversais definidos pelos Parâmetros Curriculares Nacionais (PCNs) propõem a inserção de experiências vividas pelas crianças ou jovens nos conteúdos das diversas disciplinas. Dentre os temas transversais propostos está a pluralidade cultural, que pode ser abordada no sentido de valorizar a identidade cultural de uma dada região. Utilizar as tecnologias que estão presentes no dia a dia dos estudantes, como celulares, smartphones, tablets, laptops, para divulgar a cultura regional pode auxiliar o professor na abordagem destes temas transversais. Neste contexto, o objetivo do trabalho é desenvolver um material didático composto por um e-book e um jogo educativo abordando a cultura da Região Norte. O e-book com o título "Bits e bytes de cultura da Amazônia" apresenta as danças, as lendas, a culinária e o vocabulário da Região Norte. O jogo tem como proposta a integração do tema com as diversas disciplinas. $O$ material está sendo desenvolvido seguindo os princípios e práticas do desenvolvimento de software educativo através do processo P@PSEduc e das ferramentas livre Sigil 0.7.4 e GameSalad.
\end{abstract}

Palavras-chave: eBook, jogo educacional, cultura regional.

\begin{abstract}
The cross-cutting themes defined by the National Curriculum Parameters (PCNs) propose the inclusion of experiences lived by children or young people in the contents of the various disciplines.Among the proposed cross-cutting themes are cultural diversity, which can be addressed in order to enhance the cultural identity of a given region. Use technologies that are present in everyday life of students, like cell phones, smartphones, tablets, laptops, to publicize the regional culture can help teachers in addressing these cross-cutting themes. In this context, the objective is to develop a teaching material consists of an e-book and an educational game addressing the culture of the North. The e-book called "Bits and bytes of Amazonian culture" and presents dances, legends, cuisine and vocabulary of Northern Region. The game proposes the theme of integration of the various disciplines. The material will be developed following the principles and practices of educational software development through the process P@PSEduc and free tools Sigil 0.7.4 and GameSalad.
\end{abstract}

Keyword: eBook, educational game, regional culture. 


\section{CBIE-LACLO 2015}

Anais dos Workshops do IV Congresso Brasileiro de Informática na Educação (CBIE 2015)

\section{Introdução}

As questões sociais são uma crescente dentro da educação nas escolas, estimulando a reflexão dos alunos a respeito de temas que favorecem a compreensão da realidade e a participação social dos mesmos. Os Parâmetros Curriculares Nacionais (PCNs) elegeram a inclusão de temas transversais como Ética, Pluralidade Cultural, Meio Ambiente, Saúde e Orientação sexual, com a justificativa de que o currículo escolar ganha flexibilidade, pois os temas podem ser contextualizados de acordo com as diferentes regiões, atendendo as necessidades educacionais locais [BRASIL, 1997].

Tendo em vista a importância de exaltar a educação para a cidadania dentro das escolas, que a compreensão dos temas transversais torna-se essencial. Para tanto, a busca por métodos que auxiliem neste processo de ensino e aprendizagem tem destacado tecnologias como livros digitais e jogos educativos. Ambos funcionam como mecanismos pedagógicos e didáticos que auxiliam no aprendizado de diversos temas do currículo escolar.

Por outro lado, a inserção dos mesmos nos processos de ensino e aprendizagem gera certa polêmica, como por exemplo, a substituição dos materiais impressos: livros, apostilas, manuais, etc., pelo material digital. Mesmo ressaltando-se alguns benefícios dos livros digitais como: a facilidade de reunir em um único dispositivo uma variedade de títulos, a diminuição do volume a ser transportado, dentre outros; ainda existem incertezas quanto a sua aceitação. Conforme Valente:

[...] o advento do computador na educação provocou o questionamento dos métodos e da prática educacional. Também provocou insegurança em alguns professores menos informados que receiam e refutam o uso do computador na sala de aula. Entre outras coisas, esses professores pensam que serão substituídos pela máquina. Além disso, o custo financeiro para implantar e manter laboratórios de computadores exige que os administradores adicionem alguma verba ao já minguado orçamento da escola. Finalmente, os pais exigem o uso do computador na escola, já que seus filhos, os futuros membros da sociedade do século 21, devem estar familiarizados com essa tecnologia. [VALENTE, 2002].

Uma das maiores críticas é a dificuldade de leitura devido aos diversos tamanhos das telas sendo necessária a apresentação do conteúdo de forma adequada e com qualidade, adaptando-se a cada meio de leitura, sejam desktops, tablets, leitores digitais, celulares, etc.

A propagação do uso destes dispositivos nas escolas sugere a necessidade de digitalizar o material didático disponível, que até o momento apresenta-se em sua grande maioria na forma física, isto é, impressa.

O livro digital ou $e$-book surge como uma forma de dinamizar a leitura de um livro em formato impresso; pode-se ler a versão digital do mesmo livro em um e-reader, tablet, smartphone ou computador; pode-se ainda ouvir a mesma obra em formato de áudio. $\mathrm{O}$ conteúdo será o mesmo, ainda que um ou outro detalhe escape em cada uma das leituras.

Outro recurso que tem estado presente nas salas de aula como um instrumento de auxílio à aprendizagem dos discentes são os jogos educacionais. Construídos com o objetivo de proporcionar aulas mais agradáveis e motivadoras. Os mesmos colaboram com a fixação do conteúdo através do dinamismo, resgatando a ludicidade e transformando o processo do aprender, podendo atingir um melhor rendimento dos alunos. Um dos fatores importantes em utilizar um material de apoio às práticas pedagógicas é a capacidade de ajudar o professor a reter a atenção dos alunos e ao mesmo torná-lo facilitador da aprendizagem, estimulando visualmente os alunos através das animações, cores e movimentos. [SCOLARI e BERNADI, 2007]. 


\section{CBIE-LACLO 2015}

Anais dos Workshops do IV Congresso Brasileiro de Informática na Educação (CBIE 2015)

Neste processo, o desenvolvimento de um software educativo que atenda às necessidades escolares exige cuidados adicionais aqueles de um sistema comercial ou de um site web. É necessária atenção aos mecanismos pedagógicos e didáticos, que constituem a base de todo o instrumento de ensino e de aprendizagem. É preciso, também, o envolvimento interdisciplinar de profissionais como: psicólogos, pedagogos, professores especialistas na área do conhecimento, técnicos da área computacional, entre outros. Levando em consideração os cuidados técnicos e pedagógicos que devem ser tomados na produção de um material educacional, mencionados na seção 4.

Desta forma, as teorias de aprendizagem discutidas no meio educacional devem repensar o meio de como estabelecer o elo entre o meio (tecnologia) e o fim (aprendizado), para que o aluno não seja apenas um receptor de informações, mas interaja de modo a construir seu conhecimento utilizando os recursos tecnológicos.

A proposta deste trabalho é desenvolver um material educativo, composto por um ebook e um jogo, chamado "Uma Experiência na Região Norte", que aborda de maneira didática aspectos culturais da região Norte, como as danças, lendas, culinária e vocabulário, tendo a produção gerenciada por um Processo Ágil para Software Educativo (P@PSEduc). O e-book será desenvolvido com auxílio da ferramenta livre Sigil0.7.4 e o jogo pelo software GameSalad.

O artigo está disposto em seções, onde após a introdução está a segunda seção que aborda sobre materiais educativos como os livros digitais e o jogo. Na seção três são apresentadas as diretrizes dos PCNs e os Temas Transversais. A penúltima seção aborda a metodologia para o desenvolvimento do material educativo e finaliza com a conclusão.

\section{Materiais Educativos: Livro Digital e Jogos.}

Para Garrish (2011), o Livro Eletrônico, ou e-book, é o conceito aplicado a forma de apresentação de livros através de dispositivos eletrônicos. Essa definição existe há décadas e, atualmente, ocupa um lugar significativo no mercado mundial.

A estruturação do livro ainda é semelhante a tradicional, pois contêm páginas, capa, sumário, índice, capítulos e outros elementos. No entanto, as principais diferenças surgem quando se faz uma comparação mais profunda entre eles. O preço de fabricação de livros digitais é reduzido por economizar custos em etapas de produção, como impressão, transporte e outros, necessárias em livros impressos. O peso é outro fator significativo para os livros digitais e em decorrência, o transporte também é facilitado por esse aspecto, pois o livro pode ser transportado através da internet, facilitando a entrega do produto (GARRISH, 2012). O conteúdo desses livros apresenta maior interatividade com o leitor, pois é possível aplicar mídias digitais, sejam vídeos, áudio ou imagens (GARRISH, 2013), agregando valor ao produto.

O livro digital atualmente representa para a sociedade inovação tecnológica. Popularizou-se pelos recursos que apresenta atraindo um maior número de pessoas para a prática da leitura, bem como para reconquista de antigos leitores. Seu crescimento e popularização devem auxiliar estudantes e professores, uma vez que o acesso ao acervo bibliotecário é facilitado. Segundo Milarch: 


\section{CBIE-LACLO 2015}

Anais dos Workshops do IV Congresso Brasileiro de Informática na Educação (CBIE 2015)

Sabemos que o livro impresso também possui um espaço concreto onde a informação se apresenta. Contudo, o livro digital, além da economia de papel, garante maior agilidade em termos de atualização de conteúdo. Isso é de suma importância ante o dinamismo do mundo atual. E mais: o hipertexto e a interatividade contidos neste formato permitem uma imersão e navegação em qualquer direção, abrindo caminhos personalizados de leitura e interação [MILARCH, 2012].

Além disto, é importante a escola trabalhar com diferentes linguagens lúdicas, porque possibilita compreender o mundo, expressar ideias, como no caso também do jogo educativo, considerado um instrumento construcionista que propicia a simulação de um panorama com todas as regras que regem o mesmo, permitem a formação de grupos cooperativos empregando a ferramenta lúdica como forma de atrair a atenção [CANAL DO PROFESSOR, 2013].

Estes instrumentos construcionistas estão centrados na aprendizagem, pois promovem ao indivíduo a chance de adquirir conhecimento e atuam incentivando o uso do mesmo para construir algo, pois "dando-se às crianças boas coisas para se fazer elas poderão ,aprender fazendo" muito melhor do que [aprendiam]antes" [PAPERT, 1980, parte 1].

A teoria construcionista busca meios de aprendizagem que valorizem a construção das estruturas cognitivas do sujeito a partir de suas ações. Segundo Papert, a teoria é definida pela construção do conhecimento por meio do computador, onde este torna-se um elemento de “...interação que propicia o desenvolvimento da autonomia do aluno, não direcionando a sua ação, mas auxiliando-o na construção de conhecimentos de distintas áreas do saber" [ALMEIDA, 1999, p. 29].

Os Jogos pedagógicos podem, neste contexto, contribuir para um resgate do interesse e do gosto dos alunos pela aprendizagem. Os mesmos podem servir muito mais do que apenas ao entretenimento, como por exemplo, prestar suporte que atinja níveis mais complexos no desenvolvimento cognitivo e intelectual. Por conseguinte, apresentados como bons auxiliares na construção do conhecimento se trabalhados de modo objetivo e correto.

Diante das mudanças, nas formas de se ensinar e de aprender, o que se observa é a dificuldade que os educadores têm de inserir em suas práticas educacionais o uso de material didático no formato digital. Programas do governo federal como UCA (Um Computador por Aluno) e mais recentemente a adesão de muitas escolas à prática de distribuição de tablets para os alunos são ações que exigem uma preparação dos professores para esta nova realidade. Conforme afirma Andrade (2012), "o investimento na aquisição e manutenção de equipamentos é importante para a inclusão digital, mas é essencial o investimento na formação continuada do professor". Molin e Raabe complementam:

[...] a introdução das TICs na escola traz desafios para o professor, entre eles, saber como tirar o melhor proveito delas, já que podem ser utilizadas apenas como meio para transmissão de informações ou reprodutora de práticas descontextualizadas das situações comunicativas e de aprendizagem em sala de aula [...] é primordial a criação de espaços em que os docentes possam refletir sobre o porquê e para que utilizar as tecnologias, além de proporcionar oportunidades para que desenvolvam competências que os habilitem a incorporar, criticamente, os novos recursos tecnológicos no processo pedagógico, haja vista inúmeras pesquisas comprovarem tal necessidade. [MOLIN e RAABE 2012].

É necessário que o professor saiba como encontrar, avaliar e disponibilizar o conteúdo no formato digital considerando os recursos tecnológicos que dispõe, para que seus alunos tenham em mãos, em seus celulares, smartphones, tablets, seja qual for o meio, material de boa 


\section{CBIE-LACLO 2015}

Anais dos Workshops do IV Congresso Brasileiro de Informática na Educação (CBIE 2015)

qualidade e útil para o processo de ensino e aprendizagem. Estes dispositivos acabam proporcionando experiências únicas de leitura e entretenimento, devido a interatividade que apresentam, tais como instrumentos de busca, compartilhamento em redes, produção colaborativa, consultas complementares, etc.

\section{Os Parâmetros Curriculares Nacionais (PCNs) e os Temas Transversais.}

Os PCNs do ensino fundamental têm como alguns de seus principais objetivos proporcionarem aos escolares a compreensão da cidadania como participação social e política, incentivar o posicionamento crítico construtivo nas diversas situações sociais, conhecer as características materiais, sociais e culturais do Brasil e valorizar a pluralidade do patrimônio sociocultural do país, respeitando as diferenças existentes [BRASIL 1997].

Diante destes compromissos, os PCNs decidiram incorporar aos temas transversais que são assuntos amplos correspondentes a questões sociais cotidianas - outros temas importantes que tratam da Ética, Pluralidade Cultural, do Meio Ambiente, Saúde e da Orientação Sexual. A eleição desses conteúdos destaca a urgência de se discutir nas escolas questões a respeito do preconceito, da cultura, da saúde, da violência, e do uso dos recursos naturais [BRASIL 1997].

Os temas transversais são assim chamados por que eles atravessam os diversos campos do conhecimento e nenhuma área, sozinha, é suficiente para abordá-los. As questões neles levantadas devem ser tratadas de forma integrada e contínua, fazendo relações com as diferentes extensões convencionais do saber à atualidade. O tema Pluralidade Cultural, em especial, destaca a diversidade brasileira nos aspectos sociais, culturais, de crenças, de etnia, etc., que apresenta como consequências o preconceito e a discriminação [BRASIL 1997].

A proposta deste tema às escolas é estimular a valorização da riqueza cultural do país, ressaltando sempre a própria cultura e respeitando as demais, superando qualquer expressão preconceituosa. O ensino tradicional nas escolas precisa inovar, e isto é possível a partir do momento em que a cultura regional é elencada aos conteúdos convencionais e é feita uma relação interdisciplinar com o mesmo, promovendo a construção de novas visões e atitudes aos docentes e discentes [SOUZA e ROJAS, 2011].

\section{Metodologia para o Desenvolvimento do Material Educativo}

Os Parâmetros Curriculares Nacionais apresentam os objetivos que o ensino fundamental deve atingir. Um deles é fazer conhecer e valorizar a pluralidade do patrimônio sociocultural brasileiro. Outro ponto pertinente, neste contexto, abre caminhos para se trabalhar com recursos tecnológicos dentro do espaço escolar, pois possibilita ao aluno lidar com diferentes fontes de informação para adquirir e construir conhecimentos [BRASIL, 1997, p. 6].

Com base nisto, a produção de material que satisfaça esses requisitos se faz necessária, de modo que o professor tenha ferramentas que o auxilie em suas propostas pedagógicas.

$\mathrm{O}$ material educativo visa atingir os fatores estabelecidos pelo PNCs, mencionados anteriormente. O mesmo é composto por um e-book e um jogo e ambos estão sendo desenvolvidos seguindo os princípios de um Processo Ágil para Software Educativo P@PSEduc [GELLER, CORRÊA SOBRINHO e ARAUJO 2009), que gerencia o desenvolvimento do produto desde o planejamento até a entrega.

\subsection{Critérios para o Desenvolvimento do Material Educativo.}

Em se tratando de material educacional, a definição, a adequação e a facilidade de utilização dos materiais, tornam-se fatores fundamentais. Neste sentido, o desenvolvimento do presente 


\section{CBIE-LACLO 2015}

Anais dos Workshops do IV Congresso Brasileiro de Informática na Educação (CBIE 2015)

material busca obedecer aos critérios de avaliação criados, levando em consideração tanto os aspectos pedagógicos quanto os técnicos.

Dentre as tarefas necessárias para uma avaliação está a identificação da abordagem epistemológica, aspecto pedagógico. Uma das principais perspectivas epistemológicas é o construtivismo onde o desenvolvimento mental aparecerá em sua organização progressiva como uma adaptação mais precisa da realidade [PIAGET 1964, p.16]. A teoria construtivista considera que um erro corrigido com o próprio aprendiz pode ser mais produtivo do que um acerto imediato, pois comparando hipóteses e refletindo sobre a ação é que se têm novas ideias e novos conhecimentos [CASTORINA 1988].

Os aspectos técnicos, por sua vez, envolvidos no processo de avaliação, indicam qualidades relativas à sua robustez (consegue se recuperar a erros), portabilidade (capacidade de funcionar em múltiplos sistemas operacionais), sua interface (intuitiva e agradável) bem como sua documentação (registro de todos os passos, desde o planejamento até a entrega) [REATEGUI e FINCO 2010].

A utilização de critérios é relevante quando se trata de seleção bem como a produção de software educativo de modo a avaliar a qualidade do produto.

\subsection{Desenvolvimento do E-book}

O presente e-book trata sobre cultura regional, mais especificamente a cultura da Região Norte do Brasil. Uma temática desta natureza caracteriza-se por um conjunto de assuntos que aparecem transversalizados em áreas determinadas do currículo, sendo necessário um trabalho mais significativo e expressivo. [CANAL DO PROFESSOR 2014].

O objetivo do mesmo é promover o conhecimento sobre a pluralidade cultural, um dos temas transversais essenciais no currículo escolar. Neste sentido, fazendo com que discentes do sexto ano do ensino fundamental, assim definido, tenham à disposição um material como um aporte nas propostas pedagógicas desempenhadas pelo professor sobre determinado conteúdo.

O livro digital aborda de forma lúdica assuntos tratados especificamente na disciplina de Estudos Amazônicos. O material está sendo produzido no formato ePUB, como mencionado anteriormente, possibilitando, deste modo, a disponibilidade do material em diferentes dispositivos independente da plataforma de acesso utilizada pelos alunos.

O assunto está dividido em quatro capítulos: danças, comidas típicas, lendas e vocabulário, destacando informações importantes para o conhecimento dos leitores, acompanhados de imagens que caracterizam cada capítulo. O primeiro capítulo destaca quatro danças específicas da Região Norte, o Carimbó, o Siriá, o Xote Bragantino e a Marujada. O segundo capítulo aborda a culinária, enfatizando algumas comidas típicas: mandioca, goma de tapioca, tucupí, farinha, peixe, açaí e cupuaçú. O terceiro capítulo conta as estórias de algumas lendas como a Lenda do boto, Cobra Grande, Vitória-Régia, Iara e Mandioca. O quarto capítulo apresenta o vocabulário nortista e seus significados.

Dentre os recursos identificados para tornar este produto real, a ferramenta livre Sigil 0.7.4 destacou-se por sua capacidade de produzir e-books no formato ePUB, que suporta recursos midiáticos, o que torna o produto mais interativo. O Sigil foi desenvolvido com a finalidade de ser simples e de fácil usabilidade, e está em constante aprimoramento de recursos. Como todo software, ele também apresenta limitações, porém, por ter aceitação nos principais sistemas operacionais do mercado, ele torna-se uma boa alternativa para o desenvolvimento de livros digitais com qualidade [BUSE 2013].

\subsection{Desenvolvimento do jogo}

O jogo educacional possui um papel complementar na aprendizagem, diante do contexto em que vai ser inserido. Este jogo vai instigar a mente dos usuários a assimilar os conteúdos lidos 


\section{CBIE-LACLO 2015}

Anais dos Workshops do IV Congresso Brasileiro de Informática na Educação (CBIE 2015)

no e-Book. Diante das novas tecnologias, a educação pode seguir os princípios do construtivismo, na qual o aluno é o próprio construtor do seu conhecimento. Segundo Tarouco:

Os jogos educacionais se baseiam numa abordagem auto-dirigida, isto é, aquela em que o sujeito aprende por si só, através da descoberta de relações e da interação com o software. Neste cenário, o professor tem o papel de moderador, mediador do processo, dando orientações e selecionando softwares adequados e condizentes com sua prática pedagógica. [TAROUCO et. al. 2004]

O objetivo do jogo, neste contexto, é motivar os alunos a fixar os conteúdos aprendidos com a leitura do eBook. O jogo será interativo, contendo um cenário animado e um personagem controlado pelo aluno, além de apresentar uma história sobre "A Floresta Misteriosa" que servirá para envolver os alunos e contextualizar os conteúdos regionais abordados no livro. No início do jogo, os alunos serão desafiados a encontrar os tesouros espalhados pela floresta, podendo avançar somente se responderem corretamente as perguntas que surgirão no decorrer do jogo.

A metodologia utilizada para o desenvolvimento do mesmo, será a ferramenta GameSalad (versão gratuita), recomendado para jogos em 2D que podem ser exportados para diferentes plataformas. Esta ferramenta não necessita de conhecimento de linguagens de programação, e utiliza comandos gráficos, de forma a incentivar o desenvolvimento de jogos.

\subsection{Metodologia de aplicação do Produto.}

Os produtos desenvolvidos serão aplicados em uma Escola do Ensino Fundamental, na cidade de Santarém, em uma turma do sexto ano do ensino fundamental na disciplina de Estudos Amazônicos, que possui $\mathrm{X}$ matriculados. $\mathrm{O}$ objetivo é fazer com que o docente e os discentes tenham à disposição um material que sirva de apoio na fase de transição da construção do conhecimento concreto para a formação do conhecimento abstrato, tendo como foco o tema transversal cultura regional.

O planejamento do cronograma foi avaliado anteriormente pelo docente da disciplina para não haver prejuízos ao plano pedagógico do mesmo. Desta forma definiu-se que a aplicação dos produtos acontecerá em cinco momentos, correspondendo a $\mathrm{X}$ aulas semanais com duração de 45 minutos cada.

No primeiro e segundo momento, o professor deverá abordar temas específicos da Região Norte, como danças, lendas, culinárias e vocabulário, usando a metodologia tradicional de ensino, podendo utilizar apostilas ou livros. Este processo introdutório, que acontecerá em duas semanas e meia, é essencial para que os alunos tenham uma familiarização prévia com o tema, lembrando que o e-book e o jogo atuam como ferramenta auxiliar no ensino e aprendizagem, não como substitutos do professor. Ao finalizar esse processo, a turma será dividida aleatoriamente através de sorteio, para que sejam formados dois grupos: o grupo controle (GC) e o grupo experimental (GE), afim de manter a imparcialidade dos resultados.

O terceiro momento acontecerá em 45 minutos, onde, após a divisão, o GE terá contato com os materiais que estarão disponíveis no laboratório de informática da Universidade de Ensino Superior dos pesquisadores, acompanhados pelo professor. Quanto o GC, será direcionado à biblioteca para ter acesso aos livros ou apostilas passados nas aulas anteriores, sob a supervisão da bibliotecária. Sendo que em outro momento, os mesmos, também, terão a oportunidade de mais uma aula, com o professor presente, para fazer a revisão com os materiais utilizados anteriormente na biblioteca, de modo que ambos os grupos tenham oportunidades iguais. 


\section{CBIE-LACLO 2015}

Anais dos Workshops do IV Congresso Brasileiro de Informática na Educação (CBIE 2015)

Nos próximos 45 minutos, os dois grupos farão um teste formulado pelo docente, acerca do tema cultura regional, por meio do qual serão avaliados em relação ao desempenho, analisando-se o aproveitamento de cada grupo.

\section{Conclusão}

A inserção de recursos digitais no ambiente educacional se explica pelo fato de a atual geração já nascer sob grande influência das tecnologias. [SILVA, SILVA e CORRÊA SOBRINHO 2014]. Para Mendelsonh (1997) as crianças nascem em uma cultura que se clica e o dever dos professores é inserir-se no universo de seus alunos.

Neste sentido, faz-se necessário a produção de material dessa natureza com intuito de servir como uma alternativa a mais a favor do professor e de apoio para o aluno, visto que a gama de dispositivos está cada vez mais presente nas atividades desempenhadas pelo ser humano, então por que não na educação?

O material educativo proposto, neste processo, será desenvolvido por alunos do curso de Sistemas de Informação com acompanhamento de uma Pedagoga em cada uma das fases: planejamento, modelagem, desenvolvimento e encerramento. Os ajustes necessários tanto no e-book quanto no jogo estão sendo feitos pelo professor que ministra a disciplina de Estudos Amazônicos de modo a contribuir diretamente na proposta pedagógica do mesmo. Cabe dizer que apesar do material ser produzido e posteriormente validado na disciplina mencionada, o mesmo terá finalidade multidisciplinar, pois aborda conteúdo transversal, podendo ser utilizado nas diversas disciplinas como geografia, história, português e matemática.

Este processo resultará em um software que atenda não só a parte técnica de animações e interações, mas que contemple a essência do material de suporte pedagógico como metodologia de ensino e aprendizagem.

Tendo resultado positivo na experiência com o tema transversal "cultura regional", outros temas transversais podem ser elaborados com a mesma metodologia. Como trabalhos futuros pretende-se dar continuidade no projeto com intuito de que os docentes não somente usem, mas consigam produzir o seu próprio material, sem muita experiência técnica, pois, tomando conhecimento dos resultados positivos dos mesmos dentro do contexto escolar, a equipe acredita que o professor sentir-se-á motivado a desenvolver.

\section{REFERÊNCIAS}

Almeida, M. (1999) “O Aprender e a informática: a arte do possível na visão do professor”. In: Cadernos Informática para a mudança em educação. MEC/SEED/PROINFO.

Andrade, E.D. et al. (2012) “O Pedagogo e as Novas Tecnologias”.In Anais do XVIII WIE. Rio de Janeiro: novembro de 2012. Disponível em: <http://www.brie.org/pub/index.php/wie/article/view/2106>. Acesso em: 20 Mai. 2015.

Brasil. Secretaria de Educação Fundamental. (1997) "Parâmetros Curriculares Nacionais: apresentação dos temas transversais". Brasília: MEC/SEF. Disponível em: Disponível em : 〈http://portal.mec.gov.br/seb/arquivos/pdf/livro081.pdf〉. Acessoem 18 de Maio de 2015.

Buse, Jarret W. (2013) “Epub from the Ground Up: A Hands-on Guide to EPUB 2". New York: McGraw-Hill.

Castorina, J. (1988) "Psicologia Genética: aspectos metodológicos e implicações pedagógicas. Porto Alegre: Artes Médicas. 


\section{CBIE-LACLO 2015}

Anais dos Workshops do IV Congresso Brasileiro de Informática na Educação (CBIE 2015)

Garrish, Matt. (2012) “Accessible EPUB 3”.Sebastopol: O'Reilly.

Garrish, Matt; Gylling, Markus. (2013) “EPUB 3 best practices”.Sebastopol: O'Reilly

Garrish, Matt. (2011) "What is EPUB 3?”. Sebastopol: O'Reilly.

Geller, M. T. B.; Correa Sobrinho, M.; Araujo, C. A. P. (2009) "Proposta de Customização de um Processo para Desenvolvimento de Software Educativo.” In $20^{\circ}$ Simpósio Brasileiro de Informática na Educação. Florianópolis, 2009.

Milarch, Vilson. (2012) "Livros digitais na educação perspectivas e desafios". Disponível em: <http://www.congressodolivrodigital.com.br/blog/wp-content/TC-vilson-milarch70312112353.doc>. Acesso em: 20 de Maio de 2015.

Molin, Suênia I.L; Raabe, Andre. (2012)"Novas Tecnologias na Educação: Transformações da Prática Pedagógica no Discurso do Professor”. In Anais do XVIII SBIE.

Papert, S. (1980) "Constructionism versus instructionism". Disponível em: <http://www.papert.org/articles/const_inst/const_inst1.html>. Acesso em: 24 Mai. 2015.

Piaget, J. (1964) "Seis estudos de psicologia”. Forense: Rio de Janeiro.

Reategui, E; Finco, D. M. (2010) "Proposta de diretrizes para a avaliação de Objetos de Aprendizagem. RENOTE: Revista de Novas Tecnologias educacionais. Porto Alegre: UFRGS. Disponível em: <http://seer.ufrgs.br/renote/article/view/18066>. Acesso em: 18 Mai. 2015.

Silva, D. E; Silva, V.O; Correa Sobrinho, M. (2014) "Produção de um Objeto de Aprendizagem para ensino da Língua Inglesa". In Anais do XVII Congresso Internacional EDUTEC. Disponível em: <http://hdl.handle.net/10396/12465>. Acesso em: 11 Mai. 2015.

Tarouco et. al. (2004) "Jogos Educacionais". CITED: UFRGS. Disponível em: <http://www.cinted.ufrgs.br/ciclo3/af/30-jogoseducacionais.pdf >. Acesso em: 24 Mai. 2015.

Souza, Maria N. G., Rojas, Jucimara. (2011) “A Cultura na Sala de Aula e a Interdisciplinaridade”. Revista NUPEM. Campo Mourão, v.3, n.5, ago/dez. Disponível em: $<$ http://www.fecilcam.br/revista//index.php/nupem/article/viewFile/66/47>. Acesso em 22 de Maio de 2015. 